\title{
Avaliação da pré-triagem sorológica para o marcador do vírus da hepatite B (anti-HBc total) em candidatos à doação de sangue no Estado do Acre, 2002
}

\author{
Evaluation of the sorologic pre-selection for the hepatitis B virus marker \\ (total anti-HBc) in candidates to blood donation \\ in the State of Acre, 2002
}

\author{
Rita do Socorro Uchôa da Silva ${ }^{1,2}$, Sandra Albuquerque Lima Ribeiro ${ }^{1}$, \\ Rodrigo Pinheiro Silveira ${ }^{2}$ e Milton dos Santos Freitas ${ }^{2}$
}

\begin{abstract}
RESUMO
O objetivo da pesquisa foi avaliar a pré-triagem sorológica para hepatite B (anti-HBc total) em candidatos à doação de sangue, verificando a associação entre as variáveis sexo, faixa etária, escolaridade e naturalidade. Estudo transversal com dados retrospectivos, tendo como população-alvo candidatos à doação de sangue naturais dos municípios do interior do Acre, que procuraram o Centro de Hematologia e Hemoterapia do Acre, no período de janeiro a dezembro de 2002. Dos 673 candidatos incluídos foi constatado reatividade ao anti-HBc total em 54,8\%. Sendo observado maior reatividade ao anti-HBc total entre os candidatos do sexo masculino, faixa etária mais avançada e menor grau de escolaridade $(p<0,05)$. A pré-triagem sorológica para hepatite $B$ em candidatos a doação de sangue é uma alternativa viável, visto que, reduz o custo e aumenta a segurança transfusional. A captação de doadores do sexo feminino, jovens e com grau de escolaridade acima do fundamental sinaliza potenciais doadores de sangue para o HEMOACRE.
\end{abstract}

Palavras-chaves: Hepatite B. Anti-HBc total. Doador de sangue. Triagem sorológica.

\begin{abstract}
The aim of this research was to evaluate previous serum screening for hepatitis B (total anti-HBc) among blood donation candidates, verifying the link between the variables: gender, age, degree of education and native-born. A transverse study with retrospective data carried out on a target population, blood donation candidates from districts of the interior of Acre State, who came to the Acre Hematology and Hemoterapy Center during the period January to December, 2002. The research indicated reactivity in $54.8 \%$ of the total anti-HBc among the 673 candidates included. Greater reactivity of total anti-HBc was observed among males, older candidates and those with lower education levels $(p<0.005)$. Previous serum screening for hepatitis $B$ among blood donation candidates is a viable alternative, since it reduces cost and increases transfusional safety. Attracting female donors, youths and those who have higher education levels, would signify potential blood donors for HEMOACRE.
\end{abstract}

Key-words: Hepatitis B. Total anti-HBc. Blood donor. Serum screening.

A hepatite pelo vírus $B$ representa um dos maiores problemas de saúde pública mundial, tanto por sua magnitude quanto por estar relacionada a formas crônicas, cirrose e câncer primário do fígado ${ }^{168}$. A Organização Mundial da Saúde (OMS) acredita que haja na América Latina e no Caribe, aproximadamente 400.000 novas infecções pelo vírus da hepatite $B$ a cada ano. Em relatórios de produção de hemorrede (ANVISA) ${ }^{2}$ em 1999, dentre 2.837.937 doações de sangue efetuadas no Brasil, foi demonstrada a reatividade de $0,7 \%$ ao AgHBs e $4,9 \%$ ao anti-HBc total, sendo na região norte do país, respectivamente de $0,7 \%$ e $8,8 \%$. No Estado do Acre, a Fundação Nacional de Saúde refere que há 30 casos da

1. Centro de Hematologia e Hemoterapia do Acre, Rio Branco, AC, Secretaria de Estado de Saúde do Acre, Rio Branco, AC. 2. Universidade Federal do Acre, Rio Branco, AC.

Endereço para correspondência: Dra. Rita do Socorro Uchôa da Silva. Rua Vênus 478, Morada do Sol, 69910-470 Rio Branco, AC.

e-mail: rita.uchoa@ac.gov.br; uchoarita@yahoo.com.br.

Recebido para publicação em 9/12/2004

Aceito em 25/1/2006 
doença para cada 100.000 habitantes . Porém, as informações do Centro de Hematologia e Hemoterapia do Acre (HEMOACRE) sugerem que entre doadores de sangue os índices de reatividade ao AgHBs são de 6 casos a cada 1.000 pessoas que doam sangue, chamando a atenção para a gravidade da situação no estado. Na capital do Estado do Acre, em 1996, 52,1\% das pessoas que doaram sangue foram reativas ao anti-HBc total, $38,3 \%$ em 1997 , 23,2\% em 1998 e $28 \%$ em 1999. Como o descarte de bolsas de sangue decorrente da reatividade dos exames sorológicos era extremamente elevado, sendo em 1998 de 34,2\% e a relação custo-benefício muitas vezes não compensava, foi estabelecida na tentativa de reduzir este percentual, a pré-triagem sorológica para marcador da hepatite B (anti-HBc total).

Avaliações prévias realizadas em 1999, em candidatos à doação de sangue em municípios do interior do Acre, mostraram percentuais de até $80 \%$ de reatividade ao anti-HBc total, fato que favoreceu a implantação da pré-triagem sorológica para hepatite $\mathrm{B}$, a qual consiste em submeter o candidato à doação de sangue, natural de municípios do interior do estado ao exame anti-HBc total (ELISA), após a triagem clínica. Porém, previamente à doação, que passa a ser realizada apenas naqueles cujo o teste seja negativo.

Este trabalho foi realizado com o objetivo de avaliar se a pré-triagem sorológica para hepatite B (anti-HBc total) em candidatos à doação de sangue é uma alternativa viável para a gestão da hemorrede do Acre, determinando o percentual de reatividade ao anti-HBc total entre os candidatos submetidos à pré-triagem sorológica para 0 vírus da hepatite B (VHB) e analisar a existência de associação entre reatividade ao anti$\mathrm{HBc}$ total e as variáveis: sexo, idade, grau de escolaridade e município de nascimento do candidato à doação de sangue.

\section{MATERIAL E MÉTODOS}

0 Estado do Acre faz parte da Amazônia ocidental e, segundo o Censo 2002, possui uma população de 557.337 pessoas. 0 Acre limita-se com os Estados do Amazonas e Rondônia e com as Repúblicas do Peru e da Bolívia e é formado por 22 municípios, sendo Rio Branco a capital.

Trata-se de estudo transversal com dados retrospectivos, realizado através da análise dos dados contidos nas fichas de pré-triagem sorológica para marcador do vírus da hepatite B dos candidatos à doação de sangue em Rio Branco-Acre, no período de janeiro a dezembro de 2002.

Foram selecionadas fichas de candidatos à doação de sangue provenientes do interior do Estado do Acre, que se apresentaram para sua primeira doação no hemocentro entre janeiro e dezembro de 2002. Foram excluídas aquelas que não apresentaram informações sobre $o$ ano de coleta, município de nascimento, resultado sorológico do anti-HBc total e aquelas de indivíduos provenientes de municípios com menos de três candidatos a doação. As variáveis categóricas foram analisadas pelo $\chi^{2}$ (qui-quadrado). Por se tratar de um estudo com dados retrospectivos, o mesmo foi executado a partir da obtenção da autorização da Gerência de Apoio Técnico do HEMOACRE.

\section{RESULTADOS}

Dos 673 candidatos à doação de sangue, naturais de municípios do interior do Acre, submetidos à pré-triagem sorológica para marcador do vírus da hepatite B, $72,9 \%$ eram do sexo masculino e $27,1 \%$ do feminino. A Tabela 1 mostra que os municípios com maior número de candidatos foram Sena Madureira (23,2\%), Tarauacá $(17,4 \%)$ e Cruzeiro do Sul $(14,3 \%)$.

Do total, $54,8 \%(\mathrm{n}=369)$ apresentaram reatividade ao antiHBc total. Excetuando-se os candidatos naturais de municípios nos quais houve um número extremamente reduzido de candidatos à doação na amostra analisada (Marechal Thaumaturgo, Porto Walter, Porto Acre, Mâncio Lima e Bujari) e os municípios que apresentaram candidatos com maior percentual de sorologia positiva foram Manoel Urbano (85,7\%), Feijó (65,8\%) e Sena Madureira (63,4\%), conforme descrito na Tabela 2.

A reatividade ao anti-HBc total foi significativamente maior nas faixas etárias mais avançadas (Tabela 3).

Quando se avalia a reatividade ao anti-HBc total por sexo e faixa etária, observa-se que há diferenças significativas entre os candidatos do sexo feminino na faixa etária até 20 anos entre resultados do anti-HBc total, indicando baixa reatividade nesta faixa etária específica entre as mulheres. Com relação aos candidatos do sexo masculino, as diferenças estatísticas ocorreram entre as faixas etárias de 21 e 50 anos, indicando que entre esses candidatos houve maior reatividade ao anti-HBc total, conforme pode ser observado na Tabela 4.

Tabela 1 - Características dos 673 candidatos à doação de sangue, naturais do interior do Estado do Acre, submetidos à pré-triagem sorológica para hepatite $B$, nO HEMOACRE ET 2002.

\begin{tabular}{lrc}
\hline Variáveis & Número & Porcentagem \\
\hline Gênero & & \\
$\quad$ masculino & 491 & 72,9 \\
$\quad$ feminino & 182 & 27,1 \\
Faixa etária (anos) * & & \\
$\quad$ 20 & 146 & 21,7 \\
21 a 30 & 279 & 41,6 \\
31 a 40 & 144 & 21,4 \\
41 a 50 & 80 & 11,9 \\
51 a 60 & 22 & 3,4 \\
Município de naturalidade & & \\
Manoel Urbano & 14 & 2,1 \\
Porto Acre & 3 & 0,4 \\
Feijó & 78 & 11,6 \\
Sena Madureira & 156 & 23,2 \\
Tarauacá & 117 & 17,4 \\
Brasiléia & 86 & 12,8 \\
Plácido de Castro & 22 & 3,3 \\
Cruzeiro do Sul & 673 & 14,3 \\
Assis Brasil & 11 & $\mathbf{1 0 0 , 0}$ \\
Xapuri & 84 & \\
Mâncio Lima & 66 & \\
\hline Total & & \\
\hline
\end{tabular}

Fonte: HEMOACRE, 2002.

* Em dois candidatos não havia registro da idade. 
Tabela 2 - Indice de positividade do anti-HBc total de 664 candidatos a doadores de sangue de diferentes municípios do interior do Estado do Acre em 2002.

\begin{tabular}{|c|c|c|c|c|c|}
\hline \multirow[b]{3}{*}{ Município de nascimento } & \multicolumn{4}{|c|}{ anti-HBc total* } & \multirow[b]{3}{*}{$\chi^{2} 1 \mathrm{GL}$} \\
\hline & \multicolumn{2}{|c|}{ reativos } & \multicolumn{2}{|c|}{ não reativos } & \\
\hline & $\mathrm{n}^{0}$ & $\%$ & $\mathrm{n}^{0}$ & $\%$ & \\
\hline Manoel Urbano & 12 & 85,7 & 2 & 14,3 & $7,14^{* * * *}$ \\
\hline Porto Acre & 2 & 66,7 & 1 & 33,3 & 0,33 \\
\hline Feijó & 50 & 65,8 & 26 & 34,2 & $7,58^{* * *}$ \\
\hline Sena Madureira & 97 & 63,4 & 56 & 36,6 & $10,99^{\text {*** }}$ \\
\hline Tarauacá & 67 & 58,8 & 47 & 41,2 & 3,51 \\
\hline Brasiléia & 47 & 55,9 & 37 & 44,1 & 1,19 \\
\hline Plácido de Castro & 11 & 50,0 & 11 & 50,0 & 0,00 \\
\hline Cruzeiro do Sul & 47 & 49,0 & 49 & 51,0 & 0,04 \\
\hline Assis Brasil & 4 & 36,4 & 7 & 63,6 & 0,82 \\
\hline Xapuri & 28 & 34,1 & 54 & 65,9 & $8,24^{\text {*** }}$ \\
\hline Mâncio Lima & 2 & 33,3 & 4 & 66,7 & 0,67 \\
\hline Total & 369 & 55,6 & 295 & 44,4 & $8,25^{\text {*** }}$ \\
\hline
\end{tabular}

Fonte: HEMOACRE, 2003.

* Excluídos 09 candidatos com resultados inconclusivos.

*** $\mathrm{p}<0,05$

Tabela 3 - Distribuição, segundo a faixa etária e resultado do anti-HBc total de 662 candidatos à doação de sangue que foram submetidos à pré-triagem sorológica para hepatite B, no HEMOACRE, em 2002.

\begin{tabular}{|c|c|c|c|c|c|c|}
\hline \multirow[b]{3}{*}{ Faixa etária (anos) } & \multicolumn{4}{|c|}{ anti-HBc total * } & \multirow[b]{3}{*}{ Total } & \multirow[b]{3}{*}{$\chi^{2} 1 \mathrm{GL}$} \\
\hline & \multicolumn{2}{|c|}{ Reativo } & \multicolumn{2}{|c|}{ Não reativo } & & \\
\hline & $\mathrm{n}^{0}$ & $\%$ & $\mathrm{n}^{0}$ & $\%$ & & \\
\hline$\leq 20$ & 55 & 37,9 & 90 & 62,1 & 145 & $8,45^{* * * *}$ \\
\hline 21 a 30 & 147 & 53,6 & 126 & 46,4 & 273 & 1,62 \\
\hline 31 a 40 & 97 & 67,5 & 46 & 32,5 & 143 & $18,19^{\text {*** }}$ \\
\hline 41 a 50 & 52 & 65,4 & 27 & 34,6 & 79 & $7,91^{\text {** }}$ \\
\hline 51 a 60 & 16 & 72,7 & 6 & 27,3 & 22 & $4,55^{\text {*** }}$ \\
\hline Total & 367 & 55,4 & 295 & 44,6 & 662 & $7,83^{\text {*** }}$ \\
\hline
\end{tabular}

Fonte: HEMOACRE, 2003.

* Excluídos 9 candidatos que obtiveram resultados do anti-HBc total inconclusivos e 2 sem informações sobre a idade.

$* * \mathrm{p}<0,05$

Tabela 4 - Índice de positividade do anti-HBc de 662 candidatos à doação de sangue, segundo a faixa etária e sexo.

\begin{tabular}{|c|c|c|c|c|c|}
\hline \multirow[b]{3}{*}{ Masculino } & \multicolumn{4}{|c|}{ anti-HBc total } & \multirow[b]{3}{*}{ Total } \\
\hline & \multicolumn{2}{|c|}{ reativo } & \multicolumn{2}{|c|}{ não reativo } & \\
\hline & $\mathrm{n}^{0}$ & $\%$ & $\mathrm{n}^{0}$ & $\%$ & \\
\hline$\leq 20$ anos & 49 & 41,2 & 70 & 58,8 & 119 \\
\hline 21 a 30 anos & 115 & 59,9 & 77 & 40,1 & 192 \\
\hline 31 a 40 anos & 77 & 75,5 & 25 & 24.5 & 102 \\
\hline 41 a 50 anos & 41 & 70,7 & 17 & 29,3 & 58 \\
\hline 51 a 60 anos & 9 & 69,2 & 4 & 30,8 & 13 \\
\hline Total & 291 & 60,1 & 193 & 39,9 & 484 \\
\hline \multicolumn{6}{|c|}{$\mathrm{p}<0,05\left(\chi^{2} 1 \mathrm{GL}=19,84\right)$} \\
\hline & \multicolumn{2}{|c|}{ reativo } & \multicolumn{2}{|c|}{ não reativo } & \\
\hline Feminino & $\mathrm{n}^{0}$ & $\%$ & $\mathrm{n}^{0}$ & $\%$ & Total \\
\hline$\leq 20$ anos & 6 & 23,1 & 20 & 76,9 & 26 \\
\hline 21 a 30 anos & 32 & 39,5 & 49 & 60,5 & 81 \\
\hline 31 a 40 anos & 20 & 48,8 & 21 & 51,2 & 41 \\
\hline 41 a 50 anos & 11 & 52,4 & 10 & 47,6 & 21 \\
\hline 51 a 60 anos & 07 & 77,8 & 02 & 22,2 & 9 \\
\hline Total & 76 & 42,7 & 102 & 57,3 & 178 \\
\hline
\end{tabular}

$\mathrm{p}<0,05\left(\chi^{2} 1 \mathrm{GL}=3,80\right)$
Quanto ao grau de escolaridade, 295 (44,4\%) pessoas referiram ter até 0 fundamental completo. Foram excluídos desta análise 24 candidatos, 15 devido à falta de informação sobre o grau de escolaridade e 9 cujos resultados foram inclonclusivos ao anti-HBc total (Tabela 5).

Tabela 5 - Índice de positividade do anti-HBc de 662 candidatos à doação de sangue, segundo a escolaridade.

\begin{tabular}{|c|c|c|c|c|c|}
\hline \multirow[b]{3}{*}{ Escolaridade $* * *$} & \multicolumn{4}{|c|}{ anti-HBc total * } & \multirow[b]{3}{*}{ Total } \\
\hline & \multicolumn{2}{|c|}{ reativo } & \multicolumn{2}{|c|}{ não reativo } & \\
\hline & $\mathrm{n}^{0}$ & $\%$ & $\mathrm{n}^{0}$ & $\%$ & \\
\hline Não alfabetizado & 13 & 76,5 & 04 & 23,5 & 17 \\
\hline Fundamental incompleto & 117 & 65,0 & 63 & 35,0 & 180 \\
\hline Fundamental completo & 70 & 71,4 & 28 & 28,6 & 98 \\
\hline Médio incompleto & 34 & 50,0 & 34 & 50,0 & 68 \\
\hline Médio completo & 104 & 47,3 & 116 & 52,7 & 220 \\
\hline Superior incompleto & 17 & 34,0 & 33 & 66,0 & 50 \\
\hline Superior completo & 7 & 43,8 & 9 & 56,2 & 16 \\
\hline Total & 362 & 55,8 & 287 & 44,2 & 649 \\
\hline
\end{tabular}

Fonte: HEMOACRE, 2002.

* Excluídos 9 candidatos à doação com resultado inconclusivos ao anti-HBc total e 15 que não apresentaram registro sobre o grau de escolaridade.

$* * \mathrm{p}<0,05\left(\chi^{2} 1 \mathrm{GL}=8,67\right)$

\section{DISCUSSÃo}

0 índice de reatividade ao anti-HBc total foi elevado $(54,8 \%)$, o que contribui para afirmar que há grande circulação do vírus da hepatite B na população oriunda de municípios do interior do Acre. Como não se realizou os testes AgHBs e anti-HBs, não se pode afirmar se estas pessoas não apresentariam reatividade a algum destes marcadores, ou seja, não se pode dizer que eram portadores de hepatite $\mathrm{B}$, ou mesmo, que estavam imunes ao vírus da hepatite $B$ através da vacinação de infecção pretérita (cicatriz sorológica).

Paula e cols ${ }^{12}$, ao analisarem uma população ribeirinha nos Estados do Acre e Rondônia, detectaram prevalência de reatividade ao anti-HBc total de $66,7 \%$, percentual superior ao achado neste estudo $(54,8 \%)$. Dois fatores podem ter contribuído para tal ocorrência: a amostra naquele estudo foi constituída por pessoas dos Estados do Acre e Rondônia, além de ser formada pela população em geral, não levando em consideração contato prévio com o vírus da hepatite $B$ ou mesmo relato de sintomas da doença, diferente dos candidatos à doação de sangue que passaram por avaliação prévia, pela triagem clínica e quando se referiram a qualquer uma dessas situações, foram excluídos da pré-triagem sorológica, o que talvez possa ter contribuído para a diminuição do percentual de reatividade de nossa amostra.

Silveira e cols ${ }^{13}$ realizaram, entre 1996 e 1997, um estudo multicêntrico na América Latina, incluindo pessoas entre 1 e 40 anos de idade, no qual detectaram prevalência de $7,9 \%$ de reatividade ao anti-HBc $(\operatorname{IgG})$. Dentre as capitais brasileiras, a maior prevalência deste marcador foi encontrada em ManausAM (21\%). Porém, neste estudo, não houve a inclusão de amostras procedentes do Estado do Acre. Considerando que em 1996, o percentual de reatividade ao anti-HBc total entre doadores 
de sangue no HEMOACRE foi de 52,1\% e em 1997 de 38,3\% e supondo que houvesse a inserção de amostras de doadores de sangue do Acre no estudo de Silveira e cols ${ }^{\mathbf{1 3}}$, provavelmente Rio Branco seria a capital brasileira com maiores percentuais de reatividade ao anti-HBc total.

Entre os candidatos submetidos à pré-triagem, verificou-se que a reatividade ao anti-HBc total foi significativamente maior nas faixas etárias mais avançadas, achados condizentes aos da literatura ${ }^{591012}$. Este fato sugere que o tempo de exposição é um dos fatores que interferem para o incremento da infecção pelo vírus da hepatite $B$.

Alguns autores ${ }^{3411}$ encontraram à semelhança deste estudo, uma nítida associação entre grau de escolaridade e reatividade ao anti-HBc total, o que indica que a aquisição de conhecimentos é fundamental para que ocorra a adesão às medidas de prevenção contra o vírus da hepatite $B$.

Sugere-se a inclusão do exame AgHBs em todas as amostras de candidatos que passaram pelo processo de pré-triagem sorológica para hepatite B no HEMOACRE e que obtiveram resultados reativos ao anti-HBc total, visando a identificação de pessoas com a infecção instalada e encaminhamento para 0 acompanhamento médico.

A pré-triagem sorológica para marcador do vírus da hepatite B está sendo uma alternativa viável e importante para a hemorrede do Acre, pois tem proporcionado redução de custos em uma área de elevada endemicidade da hepatite B.

\section{AGRADECIMENTOS}

Agradecemos aos colegas do HEMOACRE pela execução do procedimento de pré-triagem clínica e sorológica dos candidatos à doação de sangue.

\section{REFERÊNCIAS BIBLIOGRÁFICAS}

1. Acosta CR. Atualización sobre hepatitis viral: etiologia, patogenia, diagnóstico microbiológico y prevención. Revista Cubana de Medicina General Integral 16: 574-584, 2000.

2. Agencia Nacional de Vigilância Sanitária (ANVISA). Relatório da produção da hemorrede de 1998, 1999 e 2000. Disponível em http:// www.anvisa.gov.br, acesso em 11 maio, Brasília, 2003.

3. Bertolini DA. Estudo da prevalência do vírus da hepatite B e seus genótipos no Estado do Paraná, Brasil. Tese de Doutorado, Escola Paulista de Medicina, Universidade Federal de São Paulo, São Paulo-SP, 2002.

4. Camejo MI, Mata G, Diaz M. Prevalencia de hepatite B, hepatitis C y sífilis en trabajadoras sexuales de Venezuela. Revista de Saúde Pública 37: 339-344, 2003.

5. Fernandes JV, Braz RFS, A Neto FV, Silva MA, Costa NF, Ferreira AM. Prevalência de marcadores sorológicos do vírus da hepatite $\mathrm{B}$ em trabalhadores do serviço hospitalar. Revista de Saúde Pública 33: 122-128, 1999.

6. Ferreira MS. Diagnóstico e tratamento de hepatite B. Revista da Sociedade Brasileira de Medicina Tropical 33: 389-400, 2000.

7. Fundação Nacional de Saúde (FUNASA). Hepatites. Situação da Prevenção e Controle das Doenças Transmissíveis no Brasil. Brasília, 2002.

8. Garcés HRH, Alvarez RFE. Hepatitis viral aguda. Revista Cubana de Medicina General Integral 14:484-493, 1998.

9. Gaze R, Carvalho DM, Werneck GL. Soroprevalência das infecções pelos vírus das hepatites A e B em Macaé 18: 1251-1259, 2002.

10. Motta-Castro, ARC; Yoshida, CFT; Lemos, ERS; Oliveira JM; Cunha, RV; LewisXimenez LL; Cabello, PH; Lima, KMB; Martins, RMB. Seroprevalence of Hepatitis B virus infection among an afro-descendant community in Brazil. Memórias do Instituto Osvaldo Cruz 98:13-17, 2003.

11. Passos ADC, Gomes UA, Figueiredo JFC, Nascimento MMP, Oliveira JM, Gaspar AMC, Yoshida CFT. Influência da migração na prevalência de marcadores sorológicos da hepatite B em comunidade rural. 2- análise comparativa de algumas características das populações estudadas. Revista de Saúde Pública 27: 36-42, 1993.

12. Paula VS, Arruda ME, Vitral CL, Gaspar AMC. Soroprevalence of viral hepatitis in riverine communities the western region of the Brazilian Amazon Basin. Memórias do Instituto Oswaldo Cruz 96: 1123-1128, 2001.

13. Silveira TR, Fonseca JC, Rivera L, Fay OH, Tapia R, Santos JI, Urdeneta E, Clemens SAC. Hepatitis B seroprevalence in Latin América. Revista Panamericana de la Salud Publica 6: 378-383, 1999. 